\title{
QUANTO VALE A ÁGUA QUE USAMOS? PROJ EÇÕES DOS IMPACTOS ECONÔMICOS DE RESTRIÇÕES AO USO E ELEVAÇÃO DE PREÇOS DA ÁGUA NA REGIÃO METROPOLITANA DE BELO HORIZONTE
}

\author{
Aline Souza Magalhães* \\ Terciane Carvalho* \\ Kênia de Souza* \\ Edson Paulo Domingues*
}

\begin{abstract}
Resumo: O problema da escassez de água no Brasil tem se intensificado nos últimos anos. Não diferente está a situação da região metropolitana de Belo Horizonte (RMBH) que presenciou a mais severa escassez hídrica de sua história em 2015. Este estudo estima o impacto econômico de restrições na oferta de água utilizando um modelo de equilíbrio geral computável interregional para os municípios da RMBH. Busca-se compreender a importância da água como insumo produtivo e no consumo das famílias, e como a limitação de seu uso afeta as decisões econômicas dos setores e das famílias. Os resultados indicam que para um corte de $1 \%$ no consumo total de água na RMBH seria necessária uma elevação média de tarifas de 7,3\%. O efeito total sobre o uso de água mostra-se bastante inelástico, uma vez que a redução de consumo é 1/ 7 da elevação dos preços.
\end{abstract}

Palavras-chave: Escassez de Água, Região Metropolitana de Belo Horizonte, Elasticidades, Equilíbrio Geral Computável.

\begin{abstract}
The shortage of water in Brazil has intensified in recent years. No different is the situation of the metropolitan region of Belo Horizonte (RMBH) who witnesses the most severe shortage of water in its history in 2015. We estimate the economic impact of restrictions on water supply using an interregional computable general equilibrium model for municipalities of the $\mathrm{RMBH}$. We seek to understand the importance of water as a productive input and in household consumption, and how the limitation of its use affects the economic decisions of sectors and households. The results indicate that for a cut of $1 \%$ in total water consumption in the RMBH, an average increase of $7.3 \%$ in water tariff would be required. The overall effect of the use of water appears to be quite inelastic since the reduction of consumption is $1 / 7$ of the rise in prices.
\end{abstract}

Key words: Water scarcity, Metropolitan region of Belo Horizonte, Elasticities, Computable general equilibrium.

\section{Classificação J EL: R10, R13, Q25,}

* Centro de Desenvolvimento e Planejamento Regional, UFMG

- Programa de Pós-Graduação em Desenvolvimento Econômico, UFPR 


\section{Introdução}

Muitas vezes o valor e a importância de um recurso natural, como a água, só se tornam perceptíveis em situações de escassez. O problema da escassez de água para consumo humano no Brasil tem se intensificado nos últimos anos. A Agência Nacional de Águas (ANA) indicou que "dos 5.565 municípios brasileiros, 55\% poderão ter déficit no abastecimento de água. Desses, $84 \%$ necessitam de investimentos para adequação de seus sistemas produtores e 16\% precisam de novos mananciais" (ANA, 2010) ${ }^{1}$.Não diferente está a situação da região metropolitana de Belo Horizonte (RMBH), terceira maior aglomeração urbana do Brasil, que presenciou a mais severa escassez hídrica de sua história em 2015, com efeitos sobre o consumo, produção e bem-estar da região metropolitana. Dadas as possibilidades reais de novas estiagens e extensão da crise hídrica no curto e longo prazo, o estudo da questão torna-se essencial para planejamento e execução de políticas públicas.

Neste contexto, o objetivo deste artigo é estimar o impacto econômico de restrições na oferta ou elevações de preços de água na RMBH. Busca-se compreender a importância da água como insumo produtivo e no consumo das famílias, e como a limitação de seu uso afeta as decisões econômicas dos setores e das famílias. O artigo também avança nessa discussão ao propor uma abordagem de equilíbrio geral no tema, considerando assim explicitamente as inter-relações de mercados, as cadeias produtivas e a heterogeneidade espacial da distribuição da atividade econômica, neste caso, na RMBH. A utilização de um modelo de Equilíbrio Geral Computável (EGC) especialmente construído para os 34 municípios da RMBH permite que diversos impactos da restrição de água sejam projetados e entendidos.

Além desta introdução, mais quatro seções compõem o artigo. A seção 2 apresenta uma contextualização das condições hídricas no Brasil e na RMBH, seguido de uma revisão de literatura sobre estudos de projeção de impactos de restrição de água. O modelo EGC utilizado é apresentado na quarta seção. A seção 5 discute as simulações e resultados obtidos. Por fim, tecem-se considerações finais.

\section{Contextualização do problema}

Problemas de escassez hídrica tem se tornado uma constante, no Brasil, nos últimos anos. Segundo o relatório de Conjuntura dos Recursos Hídricos no Brasil (ANA, 2014), houve reduções acentuadas de chuvas desde 2012 na região Nordeste e desde o final de 2013 na região Sudeste, em relação à média histórica anual. O ano de 2014 se mostrou um período de seca extrema na região Sudeste, com probabilidade de ocorrência inferior a 1\%. A partir de uma análise de balanço hídrico, o relatório apontou as Bacias Hidrográficas com trechos críticos (Figura 1). Nota-se, que esses trechos incluem além da conhecida região do Semiárido Nordestino, as bacias hidrográficas na região Sudeste (Rio Paraíba

\footnotetext{
${ }^{1}$ Atlas Brasil: abastecimento humano de água. http:// atlas.ana. gov.br/Atlas/ forms/Home.aspx
} 
do Sul, Rio Piracicaba, Rio das Velhas e Rio Doce) na qual se localizam grandes cidades brasileiras, como São Paulo, Rio de J aneiro e Belo Horizonte.

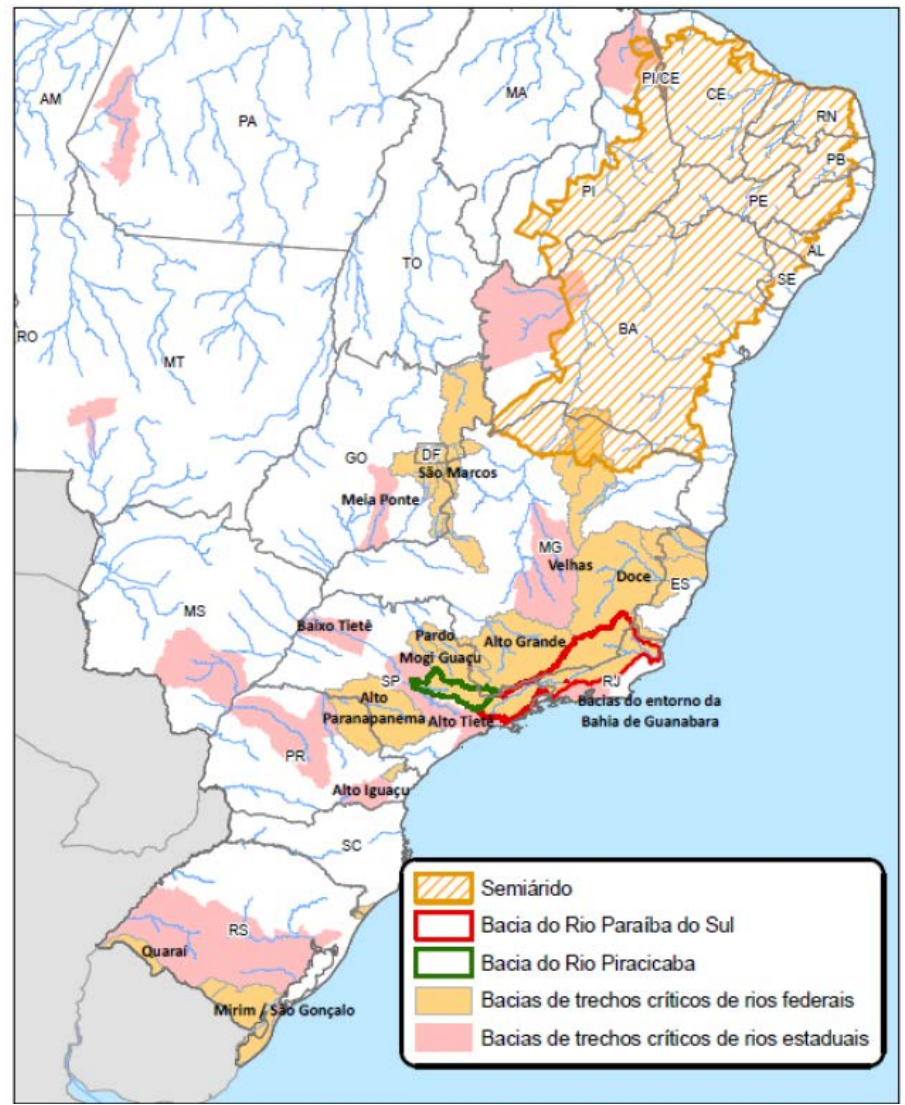

Figura 1 - Bacias de rios de domínio da União e dos Estados com trechos críticos identificados.

Fonte: ANA, 2014.

A Figura 2, por sua vez, mostra a situação de abastecimento urbano no Brasil e a grande quantidade de municípios com baixa garantia hídrica na Região Metropolitana de São Paulo, Campinas e na Baixada Santista. A oferta de água para a Região Metropolitana do Rio de Janeiro, embora não afetada diretamente, tende a ser afetada pelas interdependências dos mananciais utilizados nessas áreas, o que evidencia a importância das bacias do Alto Tietê, PCJ e Paraíba do Sul para o atendimento destas regiões. 


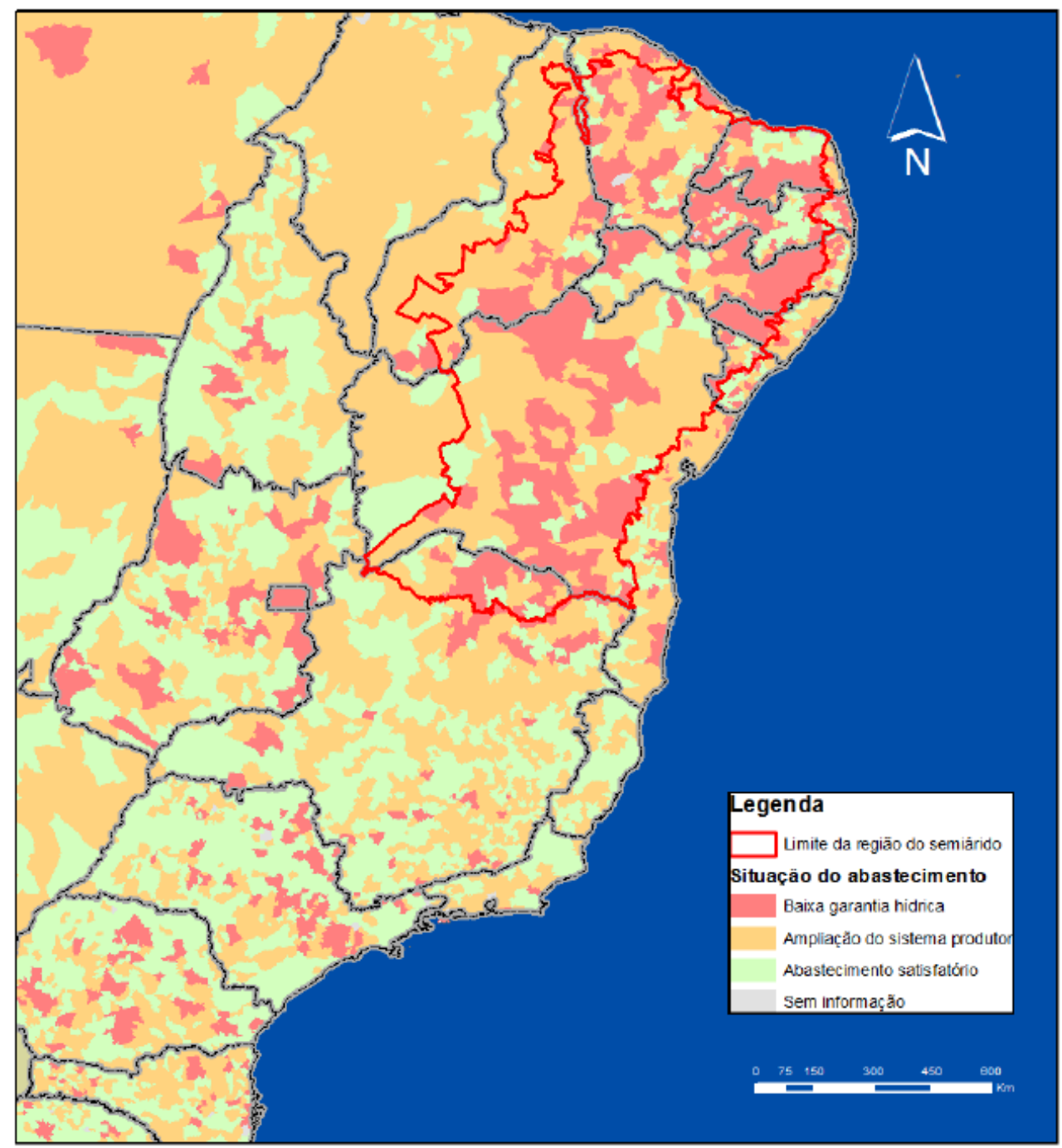

Figura 2 - Situação do abastecimento urbano de água nos munícipios brasileiros.

Fonte: ANA, 2014.

Não diferente está a situação da região metropolitana de Belo horizonte (RMBH), que presenciou a mais severa escassez hídrica de sua história em 2015. O Instituto Mineiro de Gestão das Águas (IGAM), responsável pelo gerenciamento de recursos hídricos em Minas Gerais, anunciou em abril de 2015, a situação de escassez hídrica nas porções hidrográficas que abrangem os reservatórios da região e as bacias contribuintes para estes reservatórios² .

\footnotetext{
2 Disponível em: $<$ http:// www.igam.mg.gov.br/ banco-de-noticias/ 1-ultimas-noticias/ 1552igam-declara-escassez-hidricas-em-tres-porcoes-hidrograficas-na-rmbh>Acesso em 11 de jun. de 2015.
} 
Especificamente na RMBH, composta por 34 municípios ${ }^{3}$, destacam-se os sistemas integrados Paraopeba e Rio das Velhas (Figura 3). O sistema Paraopeba inclui 3 sistemas produtores, com captações nas barragens dos rios Vargem das Flores, Serra Azul e Manso, cujas estações de tratamento possuem capacidade nominal entre 1,5 e 4,2 $\mathrm{m}^{3} / \mathrm{s}$. O sistema Rio das Velhas, que é o principal manancial da cidade de Belo Horizonte, possui capacidade de 9,0 $\mathrm{m}^{3} / \mathrm{s}$.

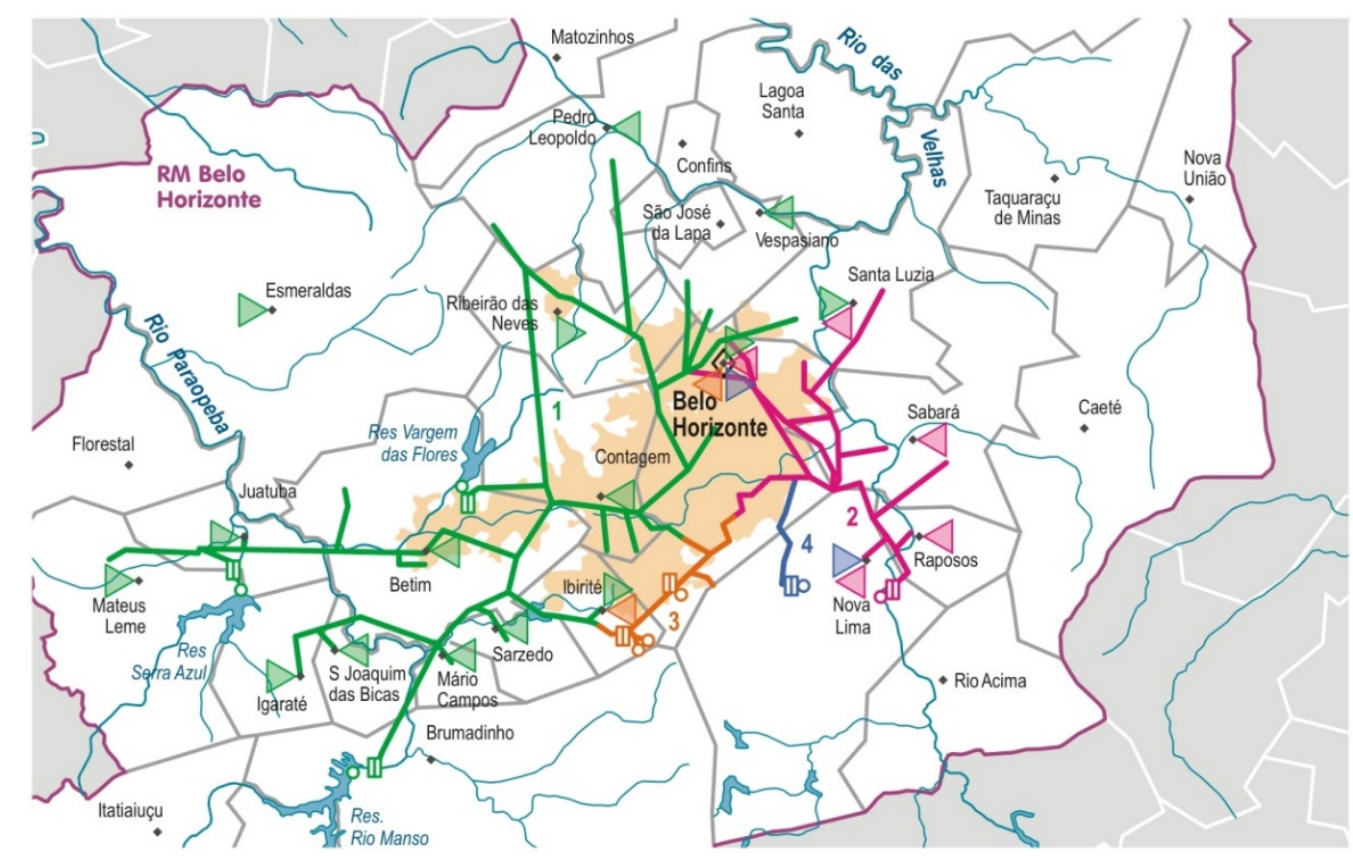

1 SIN Paraopeba (Rio Manso, Serra Azul e Vargem das Flores)

2 SIN Rio das Velhas

3 SIN Ibirité-Barreiro

4 SIN Morro Redondo

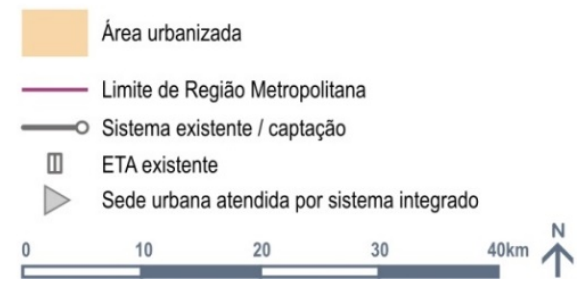

\section{Figura 3 - Sistemas de abastecimento na região metropolitana de Belo Horizonte.}

Fonte: ANA (2015)

3 A região Metropolitana de Belo Horizonte é composta pelos municípios: Baldim, Capim Branco, Jaboticatubas, Matozinhos, Florestal, Belo Horizonte, Betim, Brumadinho, Caeté, Confins, Contagem, Esmeralda, Ibirité, Igarapé, J uatuba, Lagoa Santa, Mário Campos, Mateus Leme, Nova Lima, Pedro Leopoldo, Raposos, Ribeirão das Neves, Rio Acima, Sabará, Santa Luzia, São Joaquim de Bicas, São J osé da Lapa, Sarzedo, Vespasiano, Nova União, Taquaraçu, Itaguara, Itatiaiuçu e Rio Manso. 
Segundo dados da Companhia de Saneamento de Minas Gerais (Copasa, 2015) ${ }^{4}$, o sistema Paraopeba, chegou a operar com 30\% da capacidade em 2015. No mesmo período, nos dois últimos anos, o índice era de $77 \%$ e 91\%, respectivamente. A pior situação era do reservatório de Serra Azul, cujo nível chegou a $5,2 \%$.

As portarias publicadas pelo IGAM avaliam que nesses locais há riscos acima de $70 \%$ de não atendimento aos usos de recursos hídricos estabelecidos nos reservatórios. A declaração de escassez nessas áreas também se justifica pela diminuição das precipitações nos últimos dois anos e risco real de desabastecimento na RMBH.

A declaração de risco hídrico pelo IGAM serve como critério para declaração do estado de restrição de uso de recursos hídricos. A cada segundo, 224,4 mil litros de água bruta são explorados em Minas de fontes naturais, por meio de outorgas - autorizações concedidas, gratuitamente ou a preços mínimos, a indústrias, mineradoras, produtores rurais, companhias de saneamento. Apenas $21,8 \%$ da água bruta outorgada são destinadas ao consumo humano. A maioria $(69,3 \%)$ vai para agricultura, indústria e mineração. Os que mais exploram o recurso são os que menos pagam por ele. Apenas 11 das 36 bacias hidrográficas do Estado cobram pela água captada, e o preço varia de R $\$ 0,01$ a $R \$ 0,028$ por $\mathrm{m}^{3}$ (1.000 litros) - e para usos considerados significativos (Jornal O Tempo, 2015).

Segundo o IGAM, em situações de escassez hídrica pode haver redução de volume captado nas outorgas concedidas pelo órgão ambiental. No início de 2015, a Companhia de Saneamento de Minas Gerais (Copasa), responsável pelo abastecimento na RMBH, fez campanhas para que a população economize, pelo menos, $30 \%$ no consumo de água, para evitar que medidas como racionamento e tarifa de contingência fossem implantadas. Entretanto, dado as perspectivas relacionadas as mudanças climáticas e problemas relacionados a falta de planejamento e investimento na área, há possibilidades reais no curto e longo prazo para a ocorrência de novas situações de escassez e inevitável racionamento de água, que pode tomar a forma de restrições no volume outorgado, taxas extraordinárias e/ ou rodízio de abastecimento.

\section{Revisão da literatura e Metodologia}

A água tem sido tradicionalmente vista como um recurso abundante, mas crescentes demandas a um baixo preço, conjugado a fatores climáticos e ambientais tem modificado sua categorização de "bem livre" para "bem escasso". Essa questão é potencializada pelos diferentes usuários, exacerbando o conflito que surge pelo uso para consumo humano e de animais (prioridades em tempos de escassez) e os demais usos. Isto, segundo Brouwer e Hofkes (2008) tem ampliado a procura por políticas sobre o valor econômico e as

4 Disponível em: $\langle\underline{h t t p}$ // www.copasatransparente.com.br/index.php/ nivel-dos-reservatorios/ $>$ Acesso em 7 de jun. 2015. 
consequências do gerenciamento da água. Pois mesmo sendo um recurso vital para sobrevivência, a água é frequentemente escassa.

Segundo Brouwer e Hofkes (2008), a complexidade das interações entre a água e a economia pode ser capturada por meio de modelos matemáticos que liguem processos hidrológicos às leis econômicas de oferta e demanda. O setor de agricultura, por exemplo, tem sido foco de muitos modelos que visam analisar o impacto de diferentes cenários relacionados à água, já que se trata de um setor com elevado grau de dependência deste insumo. A chave para desenvolver esses modelos econômicos é o fato de que os sistemas de água desempenham funções econômicas importantes, como insumo produtivo, nos setores de alimentos, energia, papel e metalurgia. Desse modo, como a água é utilizada para fins econômicos, o impacto de sua disponibilidade, preço e qualidade tem implicações relevantes no curto e longo prazos.

Podem-se destacar duas categorias de modelos que têm sido aplicados aos estudos que investigam os impactos econômicos do uso da água. A primeira categoria consiste em modelos de equilíbrio parcial, que segundo Brouwer e Hofkes (2008), são utilizados para incorporar mudanças no sistema hídrico e seus efeitos sobre o sistema econômico. Esses modelos se baseiam em funções de produção, em que a água é um dos insumos usados na produção e mudanças em sua disponibilidade e qualidade no processo produtivo são avaliadas a fim de se encontrar o valor marginal do uso da água. De acordo com Fadali et al. (2012), modelos de equilíbrio parcial são melhores em análises de impacto de pequenas mudanças em atributos da água que não afetem os preços de outros bens e serviços pela economia.

Não obstante, os modelos de equilíbrio parcial são limitados, pois não consideram como a política afetaria os preços relativos dos demais insumos e produtos e não conseguem apresentar a distribuição dos impactos econômicos pelos setores e regiões de uma economia. Tratar um problema econômico em equilíbrio parcial ou equilíbrio geral tem implicações metodológicas importantes. Em equilíbrio parcial a economia é um sistema econômico no qual o problema em estudo representa um bloco ou mercado, independente e isolado. As relações e o comportamento desse mercado têm pouco ou nenhum efeito no restante do sistema, e vice-versa. De fato, os trabalhos que utilizam modelos de equilíbrio parcial não conseguem capturar as interações com o resto da economia (REILLY et al., 2007).

A segunda categoria consiste nos modelos de equilíbrio geral computáveis, que são utilizados para considerações micro e macro dentro de um país para testar o efeito de diferentes políticas no uso da água, assim como o efeito de mudanças no comportamento de consumo. Os modelos EGC são construídos para representar as inter-relações entre os mercados e setores em economias regionais, onde o preço e a oferta de água podem afetar múltiplos mercados e setores. Fadali et al. (2012) afirmam que a abordagem EGC permite uma completa exploração dos efeitos de uma mudança no preço da água por toda a economia, tal que o modelo pode isolar os efeitos dessa mudança em indicadores macroeconômicos, setoriais e regionais.

Van Heerden et al. (2008), por exemplo, utilizaram um modelo estático de equilíbrio geral computável para comparar taxas sobre a demanda de água em 
dois setores, silvicultura e culturas irrigadas, na África do Sul. Berritella et al. (2007) investigaram o papel da água como fator de produção e a sua escassez no contexto do comércio internacional usando um modelo global. Segundo os autores, um entendimento do uso da água é impossível sem compreender o mercado internacional por alimentos e produtos relacionados. De modo geral, seus resultados mostram que a oferta de água reduzida implica em um aumento no preço relativos de produtos intensivos em água, beneficiando regiões que são mais abundantes em água.

Para este trabalho foi utilizado o modelo MINAS-Água. Trata-se do primeiro modelo EGC regional bottom-up estático construído para analisar os impactos da escassez hídrica em Minas Gerais. O modelo é desagregado para os 34 municípios da região metropolitana de Belo Horizonte, regiões Norte/ Nordeste, Restante do Sudeste, Sul e Centro-Oeste (totalizando 38 regiões). Desse modo, é também o primeiro modelo EGC para a região metropolitana de Belo Horizonte, trazendo aperfeiçoamentos tanto em sua base de dados como em sua especificação teórica. O modelo, por meio de sua desagregação setorial e regional, permite analisar políticas e eventos externos relacionados ao setor de água. Desse modo, captura como estes eventos podem afetar os municípios da região metropolitana em termos setoriais, regionais e macroeconômicos.

\section{O Modelo MINAS-Água: estrutura teórica}

O modelo MINAS-Água apresenta estrutura teórica semelhante ao modelo TERM, um acrônimo em inglês para The Enormous Regional Model (HORRIDGE et al., 2005). O desenvolvimento do TERM australiano também deu origem ao TERM-H2O que é utilizado para analisar problemas relacionados a políticas de gerenciamento de água na Austrália (WITTWER, 2011).

O MINAS-Água é composto por blocos de equações que determinam relações de demanda e oferta, de acordo com hipóteses de otimização e condições de equilíbrio de mercado. Além disso, vários agregados nacionais são definidos nesses blocos, como nível de emprego agregado, PIB, saldo comercial e índices de preços. Os setores produtivos minimizam os custos de produção sujeitos a uma tecnologia de retornos constantes de escala em que as combinações de insumos intermediários e fator primário (agregado) são determinados por coeficientes fixos (Leontief). Há substituição via preços entre produtos domésticos e importados na composição dos insumos via função de elasticidade de substituição constante (CES). Uma especificação CES também controla a alocação do composto doméstico entre as diversas regiões. Também ocorre substituição entre capital e trabalho na composição dos fatores primários por meio de funções CES.

Os valores dos produtos de uma determinada região direcionados para outra são compostos pelos valores básicos e pelas margens de comércio e transporte. A participação de cada margem no preço de entrega é uma combinação de origem, destino, produto e fonte (doméstico ou importado). As margens sobre os produtos de uma região para outra podem ser produzidas em diferentes regiões. Espera-se que as margens sejam distribuídas mais ou menos 
equitativamente entre origem e destino, ou entre regiões intermediárias no caso de transporte entre regiões mais distantes. Existe substituição nos fornecedores de margem de acordo com uma função CES.

No modelo, há uma família representativa para cada região, que consome bens domésticos (da própria região e das demais regiões) e bens importados. A escolha entre domésticos e importados (de outros países) é realizada por uma especificação CES (hipótese de Armington ${ }^{5}$ ). O tratamento da demanda das famílias é baseado num sistema combinado de preferências CES/Klein-Rubin. Assim, a utilidade derivada do consumo é maximizada segundo essa função de utilidade. Essa especificação dá origem ao sistema linear de gastos (LES) ${ }^{6}$, no qual a participação do gasto acima do nível de subsistência, para cada bem, representa uma proporção constante do gasto total de subsistência de cada família.

Não existe no modelo uma relação fixa entre capital e investimento e essa relação é escolhida de acordo com os requisitos específicos da simulação. No caso, assume-se que o crescimento do investimento e do capital são idênticos [Peter et al. (1996)]. As exportações setoriais respondem às curvas de demanda negativamente associadas aos custos domésticos de produção e positivamente afetadas pela expansão exógena da renda internacional, adotando-se a hipótese de país pequeno no comércio internacional. Não há uma teoria para o mercado de trabalho e a relação entre emprego e salário é escolhida conforme os objetivos da simulação. O consumo do governo é exógeno. Como existe substituição entre os fatores primários, trabalho e capital, a demanda por um fator aumenta em relação ao outro fator se o seu preço se torna relativamente mais baixo.

O MINAS-Água opera com equilíbrio de mercado para todos os bens, tanto domésticos quanto importados, assim como no mercado de fatores (capital e trabalho) em cada região. Os preços de compra para cada um dos grupos de uso em cada região (produtores, investidores, famílias, exportações e governo) são a soma dos valores básicos e dos impostos sobre vendas (diretos e indiretos) e margens (de comércio e transporte). Impostos sobre vendas são tratados como taxas ad-valorem sobre os fluxos básicos. As demandas por margens (transporte e comércio) são proporcionais aos fluxos de bens aos quais as margens estão conectadas.

\subsection{Base de Dados}

A base de dados do modelo MINAS-Água foi construída por meio de um procedimento de regionalização a partir dos dados de um modelo EGC para a

\footnotetext{
${ }^{5}$ Hipótese de Armington - bens de origens diferentes são tratados como substitutos imperfeitos. 6 O LES é adequado para amplos agregados de bens onde substituições específicas não são consideradas. Isto é, elasticidades de precos-cruzados são iguais ao efeito renda dado na equação de Slutsky sem qualquer contribuição dos efeitos de preço-cruzado. Isso implica que todos os bens são complementares fracos. O sistema linear de gastos não permite a inclusão de bens inferiores (i.e., elasticidades renda negativas).
} 
economia nacional (Referência ocultada, $\mathrm{XXXX})^{7}$. O procedimento de construção da base de dados regional se baseou na metodologia proposta em Horridge (2006), adaptado para o caso brasileiro. A partir dos dados do modelo EGC nacional, que utiliza a matriz de insumo-produto nacional de 2005 (com desagregação de 58 setores e 124 produtos), e de um grande conjunto de indicadores regionais, estimou-se uma matriz de comércio inter-regional utilizando como metodologia uma abordagem gravitacional. A principal hipótese da abordagem gravitacional ${ }^{8}$ é que o comércio inter-regional está baseado na distância entre as regiões e na interação derivada do tamanho de suas economias.

O modelo EGC nacional já distinguia os setores de energia elétrica e água em nível nacional. Este aperfeiçoamento teve como base as informações do Ministério de Minas e Energia (MME), de agências reguladoras do setor energético - especialmente a Agência Nacional do Petróleo, Gás Natural e Biocombustíveis (ANP) e a Agência Nacional de Energia Elétrica (ANEEL); além de dados complementares, sendo a principal deles o Balanço Energético Nacional Consolidado para o ano de 2005. A desagregação entre estes setores é relevante, já que o objetivo da construção do MINAS-Água é avaliar questões relacionadas aos problemas de abastecimento de água. O primeiro passo do procedimento foi transformar a base de dados em um modelo setor por setor. Para isso, a base nacional do modelo foi diagonalizada em 124 produtos e posteriormente agregada em 56 setores.

O segundo passo consistiu em um procedimento computacional de regionalização que utiliza diversos dados de participações regionais nos indicadores macroeconômicos (PIB, investimento, consumo das famílias, gastos do governo, importações, exportações). A fim de obter as participações por região, foram utilizados dados de diversas fontes: PIB por região (incluindo a divisão entre PIB da agropecuária, indústria, serviços e administração pública), divulgados pelo IBGE; exportações e importações por região existentes no sistema ALICEWEB da SECEX, e a massa salarial (por setor de atividade e região) obtida por meio da "Relação Anual de Informações Sociais" (RAIS). Além destes dados, a divisão regional para produção e consumo de água foi obtida a partir das informações do Sistema Nacional de Informações sobre Saneamento (SNIS), disponibilizado pelo Ministério das Cidades (2015). Para a energia utilizaram-se dados de distribuição de Energia Elétrica, disponibilizados pela Agência Nacional de Energia Elétrica (ANEEL). O gasto familiar de água e de energia, por sua vez, foi desagregado a partir de informações de consumo da Pesquisa de Orçamentos Familiares (POF), disponibilizada pelo IBGE (2015).

A Figura 4 mostra que o gasto com água é crescente ao longo da renda, ou seja, quanto maior a renda familiar maior o consumo de água (linha verde do gráfico). Por outro lado, em termos proporcionais, o custo com água é relativamente maior para as famílias de menor renda (linha azul). Dessa forma,

\footnotetext{
${ }^{7}$ Referência foi ocultada para evitar a identificação dos autores.

8 Uma difundida justificativa teórica à ideia de que os fluxos bilaterais de comércio dependem positivamente da renda das regiões e negativamente da distância entre elas baseia-se em um modelo de comércio desenvolvido por Krugman (1980). Maiores detalhes do método e algumas aplicações podem ser encontrados em Miller e Blair (2009).
} 
a proporção do gasto com água no consumo total de bens das famílias de menor renda é 8 vezes maior que nas famílias mais ricas, embora o consumo total de agua das famílias mais ricas seja 9 vezes maior que o consumo das famílias mais pobres.

O resultado final do procedimento é um modelo com 38 regiões (34 municípios da região metropolitana de Belo Horizonte mais 4 grandes regiões do Brasil) com total consistência da base de dados com os dados oficiais das Contas Regionais, Contas Nacionais, Matriz de Insumo-Produto, informações do IBGE; e Comércio Exterior (SECEX), Produção Industrial (PIA) e Emprego (RAIS). Para fins de apresentação dos resultados, o modelo foi agregado de acordo com os propósitos deste estudo em sete setores: Agropecuária, Indústria, Energia Elétrica e Gás, Água e Saneamento, Transporte, Comércio e Serviços.

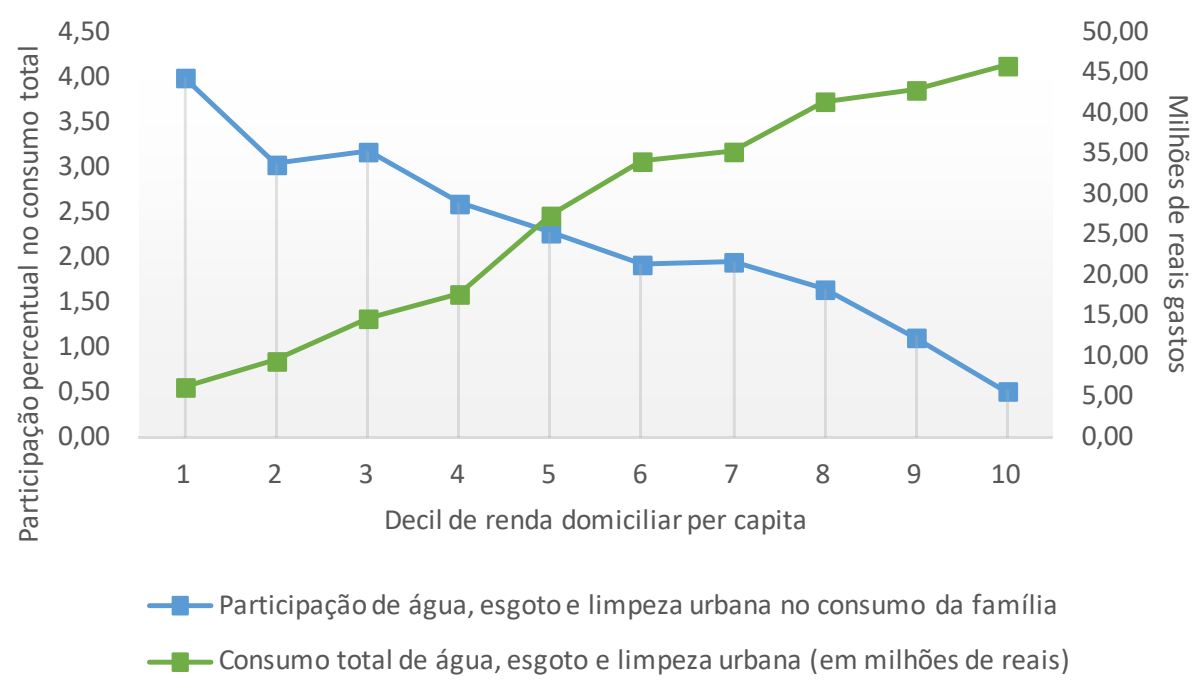

Figura 4 - Gasto familiar com o consumo de água, esgoto e limpeza urbana por decil de renda na RMBH em 2003

Fonte: Elaboração própria a partir dos dados da POF 2002/ 2003 (IBGE, 2015)

A RMBH é composta por 34 municípios, com cerca de 5 milhões de habitantes e Produto Interno Bruto de R $\$ 2,1$ bilhões de reais. O PIB per capita da RMBH é de $R \$ 24.470$, segundo dados do Censo 2010. A figura 5mostra a concentração de atividade econômica e renda na RMBH. Belo Horizonte concentra cerca de $70 \%$ do PIB da região e $48 \%$ da população. 

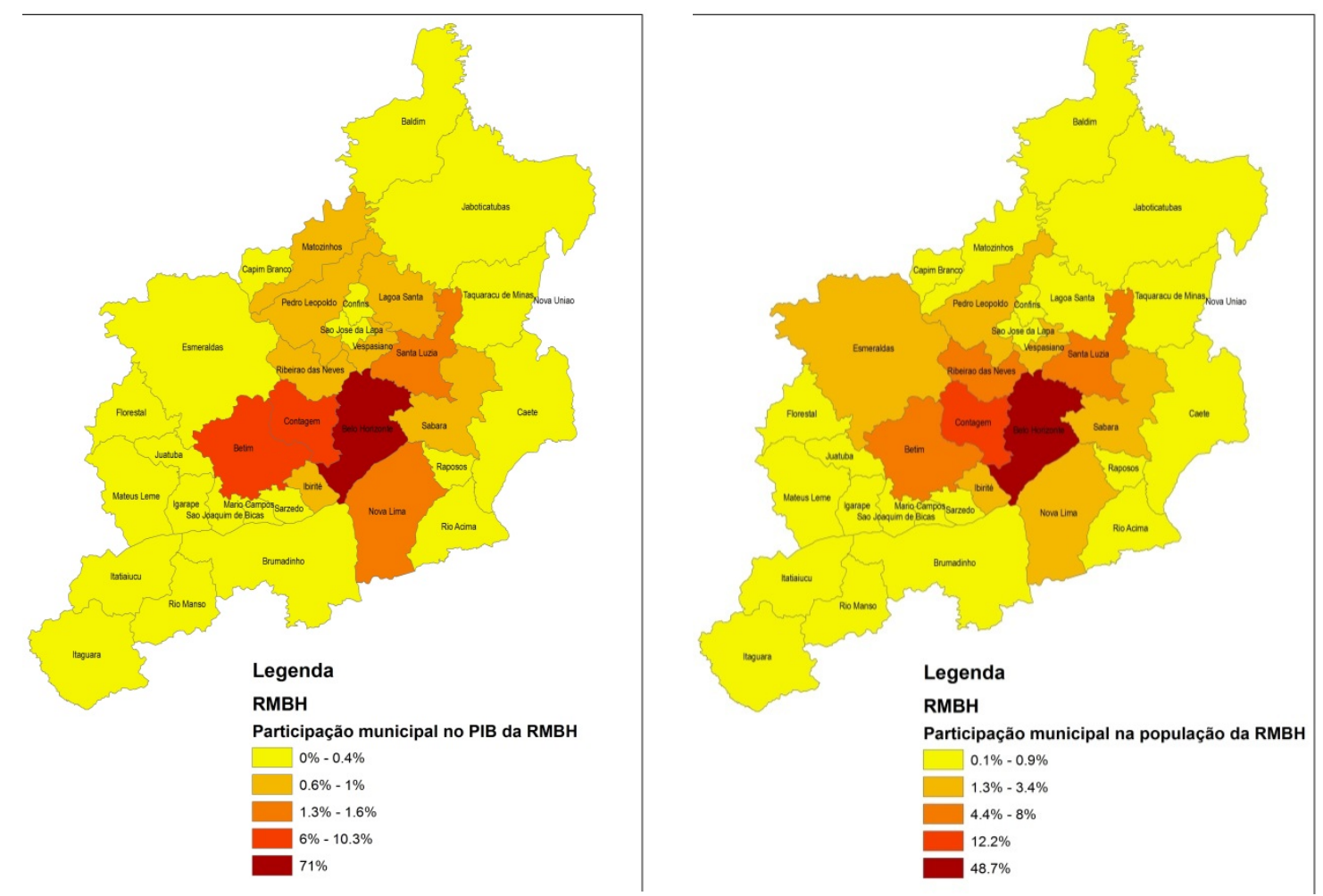

Figura 5 - PIB e população na RMBH (2005)

Fonte: Elaboração própria

A tabela 1, além de retratara participação de cada um dos municípios da RMBH em relação ao PIB e a população, traz indicadores estruturais relevantes que ajudam a explicar os efeitos espaciais dos choques de oferta hídrico. Nas duas últimas colunas, são reportadas a participação do município no uso de água residencial e o gasto com água em relação ao gasto total das famílias. Belo Horizonte, como esperado, responde por parcela significativa do uso de água residencial na $\mathrm{RMBH}$, seguida de Contagem e Betim. O gasto com água em relação ao consumo total das famílias, no entanto, revela padrões mais diferenciados. Neste caso, os municípios de Raposos, Caeté, Mario Campos e Ribeirão das Neves merecem destaque. O gasto com água em Raposos, por exemplo, representa $6 \%$ do gasto total na cesta de consumo das famílias no município, ao passo que em Belo Horizonte este gasto responde por apenas 1,1\% do total. Esta diferenciação é resultado do procedimento de regionalização da base de dados. 
Tabela 1 - PIB, população e consumo de água na RMBH - 2005

\begin{tabular}{|c|c|c|c|c|c|}
\hline \multicolumn{2}{|c|}{ Município } & \multirow{2}{*}{$\begin{array}{r}\begin{array}{c}\text { Participação } \\
\text { \% no PIB da } \\
\text { RMBH }\end{array} \\
0.20 \%\end{array}$} & \multirow{2}{*}{$\begin{array}{l}\begin{array}{c}\text { Participação } \\
\text { \% na } \\
\text { população da } \\
\text { RMBH }\end{array} \\
0.20 \%\end{array}$} & \multirow{2}{*}{$\begin{array}{r}\begin{array}{c}\text { Part. \% do } \\
\text { município no } \\
\text { uso de agua } \\
\text { residencial }\end{array} \\
0.10 \%\end{array}$} & $\begin{array}{c}\text { Part. \% do } \\
\text { gasto com água } \\
\text { no gasto total } \\
\text { das familias }\end{array}$ \\
\hline 1 & Baldim & & & & $0.60 \%$ \\
\hline 2 & Capim Branco & $0.10 \%$ & $0.20 \%$ & $0.10 \%$ & $1.30 \%$ \\
\hline 3 & Jaboticatubas & $0.20 \%$ & $0.30 \%$ & $0.30 \%$ & $1.40 \%$ \\
\hline 4 & Matozinhos & $1.00 \%$ & $0.70 \%$ & $0.60 \%$ & $0.50 \%$ \\
\hline 5 & Florestal & $0.10 \%$ & $0.10 \%$ & $0.10 \%$ & $1.00 \%$ \\
\hline 6 & Belo Horizonte & $71.00 \%$ & $48.70 \%$ & $62.70 \%$ & $1.10 \%$ \\
\hline 7 & Betim & $6.00 \%$ & $8.00 \%$ & $5.30 \%$ & $0.70 \%$ \\
\hline 8 & Brumadinho & $0.40 \%$ & $0.60 \%$ & $0.70 \%$ & $1.80 \%$ \\
\hline 9 & Caete & $0.30 \%$ & $0.80 \%$ & $1.50 \%$ & $4.40 \%$ \\
\hline 10 & Confins & $0.10 \%$ & $0.10 \%$ & $0.10 \%$ & $1.00 \%$ \\
\hline 11 & Contagem & $10.30 \%$ & $12.20 \%$ & $10.20 \%$ & $0.90 \%$ \\
\hline 12 & Esmeraldas & $0.30 \%$ & $1.30 \%$ & $0.70 \%$ & $2.30 \%$ \\
\hline 13 & Ibirité & $0.70 \%$ & $3.40 \%$ & $1.70 \%$ & $2.20 \%$ \\
\hline 14 & Igarape & $0.20 \%$ & $0.60 \%$ & $0.50 \%$ & $2.10 \%$ \\
\hline 15 & Juatuba & $0.40 \%$ & $0.40 \%$ & $0.30 \%$ & $0.70 \%$ \\
\hline 16 & Lagoa Santa & $0.60 \%$ & $0.90 \%$ & $1.00 \%$ & $1.50 \%$ \\
\hline 17 & Mario Campos & $0.00 \%$ & $0.30 \%$ & $0.20 \%$ & $3.60 \%$ \\
\hline 18 & Mateus Leme & $0.30 \%$ & $0.60 \%$ & $0.40 \%$ & $0.90 \%$ \\
\hline 19 & Nova Lima & $1.60 \%$ & $1.50 \%$ & $2.10 \%$ & $1.20 \%$ \\
\hline 20 & Pedro Leopoldo & $0.90 \%$ & $1.30 \%$ & $1.00 \%$ & $1.00 \%$ \\
\hline 21 & Raposos & $0.00 \%$ & $0.30 \%$ & $0.30 \%$ & $6.00 \%$ \\
\hline 22 & Ribeirao das Neves & $0.90 \%$ & $6.40 \%$ & $3.30 \%$ & $3.40 \%$ \\
\hline 23 & Rio Acima & $0.20 \%$ & $0.20 \%$ & $0.40 \%$ & $2.30 \%$ \\
\hline 24 & Sabara & $0.80 \%$ & $2.70 \%$ & $1.40 \%$ & $1.60 \%$ \\
\hline 25 & Santa Luzia & $1.30 \%$ & $4.40 \%$ & $2.50 \%$ & $1.70 \%$ \\
\hline 26 & Sao Joaquim de Bicas & $0.30 \%$ & $0.50 \%$ & $0.30 \%$ & $0.60 \%$ \\
\hline 27 & Sao Jose da Lapa & $0.20 \%$ & $0.40 \%$ & $0.30 \%$ & $0.90 \%$ \\
\hline 28 & Sarzedo & $0.20 \%$ & $0.50 \%$ & $0.30 \%$ & $2.10 \%$ \\
\hline 29 & Vespasiano & $0.70 \%$ & $1.90 \%$ & $1.00 \%$ & $1.10 \%$ \\
\hline 30 & Nova União & $0.10 \%$ & $0.10 \%$ & $0.10 \%$ & $0.80 \%$ \\
\hline 31 & Taquaracu de Minas & $0.10 \%$ & $0.10 \%$ & $0.10 \%$ & $0.70 \%$ \\
\hline 32 & Itaguara & $0.20 \%$ & $0.20 \%$ & $0.40 \%$ & $1.50 \%$ \\
\hline 33 & Itatiaiucu & $0.30 \%$ & $0.20 \%$ & $0.10 \%$ & $0.40 \%$ \\
\hline \multirow[t]{2}{*}{34} & Rio Manso & $0.10 \%$ & $0.10 \%$ & $0.10 \%$ & $1.20 \%$ \\
\hline & & $100.00 \%$ & $100.00 \%$ & $100.00 \%$ & $1.60 \%$ \\
\hline
\end{tabular}

Fonte: elaboração própria com os dados do modelo

A distribuição das atividades econômicas também é bastante diferenciada. A estrutura espacial da RMBH é concentrada em um centro metropolitano, formado pelo núcleo de Belo Horizonte, notadamente em razão da oferta diversificada de serviços, conforme pode-se constatar na Tabela 2. Belo Horizonte responde por mais de $80 \%$ do valor da produção setorial dos serviços. Já os municípios de Contagem e Betim formam um centro sub-regional de 
maior porte e dinamismo da $\mathrm{RMBH}$, devido à forte concentração de atividades industriais, assim como pela sua acessibilidade privilegiada. Depois de Belo Horizonte (33,8\%), Contagem e Betim concentram, respectivamente, 22,1\% e $17,5 \%$ da produção industrial. A produção agropecuária, por sua vez, é relativamente menos importante na região face aos demais setores. O município que se destaca é Florestal, produzindo cerca de $8 \%$ do total da RMBH.

Tabela 2 - Valor da produção setorial e participação dos municípios da RMBH- 2005 (R\$ milhões)

\begin{tabular}{|c|c|c|c|c|c|c|c|}
\hline \multirow{2}{*}{ Municipio } & \multicolumn{2}{|c|}{ Agropecuária } & \multicolumn{2}{|c|}{ Indústria } & \multicolumn{2}{|c|}{ Serviços } & \multirow{2}{*}{ Total } \\
\hline & R\$ milhões & Part. (\%) & $R$ Ș milhões $P$ & Part. (\%) & $\mathrm{R}$ \$̦ milhões $P$ & Part. (\%) & \\
\hline 1 Baldim & 4.3 & 0.8 & 59.8 & 0.2 & 113.7 & 0.2 & 177.8 \\
\hline 2 Capim Branco & 10.6 & 2.0 & 38.4 & 0.1 & 62.8 & 0.1 & 111.8 \\
\hline 3 Jaboticatubas & 22.4 & 4.2 & 45.6 & 0.1 & 126.9 & 0.2 & 194.8 \\
\hline 4 Matozinhos & $17.9]$ & 3.3 & $690.1 \rrbracket$ & 2.3 & 458.2 & 0.7 & $1,166.10$ \\
\hline 5 Florestal & 43.8 & 8.2 & 25.6 & 0.1 & 45.6 & 0.1 & 115 \\
\hline 6 Belo Horizonte & 203.5 & 37.9 & $10,374.50$ & 33.8 & $53,787.60$ & 80.1 & $64,365.50$ \\
\hline 7 Betim & 20.2 & 3.8 & $5,375.10$ & 17.5 & 2,189.40 \| & 3.3 & 7,584.70 \\
\hline 8 Brumadinho & 9.2 & 1.7 & 207.7 & 0.7 & 192.8 & 0.3 & 409.7 \\
\hline 9 Caete & 10.5 & 2.0 & 142.3 & 0.5 & 131.6 & 0.2 & 284.3 \\
\hline 10 Confins & 0.9 & 0.2 & 31.3 & 0.1 & 78.6 & 0.1 & 110.8 \\
\hline 11 Contagem & 62.7 & 11.7 & $6,787.60$ & 22.1 & $5,066.30 \square$ & 7.5 & $11,916.60$ \\
\hline 12 Esmeraldas & 8.8 & 1.6 & 157.9 & 0.5 & 150.7 & 0.2 & 317.4 \\
\hline 13 Ibirité & 3.6 & 0.7 & 425.3 & 1.4 & 341 & 0.5 & 769.9 \\
\hline 14 Igarape & 11.4 & 2.1 & 95.3 & 0.3 & 116 & 0.2 & 222.6 \\
\hline 15 Juatuba & 10.1 & 1.9 & 317.2 & 1.0 & 158.9 & 0.2 & 486.2 \\
\hline 16 Lagoa Santa & 6 & 1.1 & 327.2 | & 1.1 & 317.6 & 0.5 & 650.8 \\
\hline 17 Mario Campos & $7.2 \|$ & 1.3 & 10 & 0.0 & 27.2 & 0.0 & 44.4 \\
\hline 18 Mateus Leme & 6.9 & 1.3 & 348.5 & 1.1 & 91.2 & 0.1 & 446.6 \\
\hline 19 Nova Lima & 10.8 & 2.0 & 800.8 & 2.6 & 919.9| & 1.4 & $1,731.50$ \\
\hline 20 Pedro Leopoldo & 2.3 & 0.4 & $633.1 \|$ & 2.1 & 397.2 & 0.6 & $1,032.70$ \\
\hline 21 Raposos & 0.4 & 0.1 & 7.1 & 0.0 & 27.8 & 0.0 & 35.2 \\
\hline 22 Ribeirao das Neves & $9.2 \rrbracket$ & 1.7 & $462.4 \|$ & 1.5 & 489.4 & 0.7 & 960.9 \\
\hline 23 Rio Acima & 0.9 & 0.2 & 25.6 & 0.1 & 125.6 & 0.2 & 152.1 \\
\hline 24 Sabara & 3.1 & 0.6 & $517.8 \|$ & 1.7 & 379.8 & 0.6 & 900.6 \\
\hline 25 Santa Luzia & 4.5 & 0.8 & $943.1]$ & 3.1 & 574.3 & 0.9 & $1,521.90$ \\
\hline 26 Sao Joaquim de Bicas & 0.7 & 0.1 & $422.4 \|$ & 1.4 & 56.5 & 0.1 & 479.7 \\
\hline 27 Sao Jose da Lapa & 0.9 & 0.2 & 227.6 & 0.7 & 63.4 & 0.1 & 291.9 \\
\hline 28 Sarzedo & $6.9 \rrbracket$ & 1.3 & 91.1 & 0.3 & 79.3 & 0.1 & 177.2 \\
\hline 29 Vespasiano & 0.9 & 0.2 & $523.5 \llbracket$ & 1.7 & 316.2 & 0.5 & 840.5 \\
\hline 30 Nova União & 0.4 & 0.1 & 65.5 & 0.2 & 28.1 & 0.0 & 93.9 \\
\hline 31 Taquaracu de Minas & 0.7 & 0.1 & 59.8 & 0.2 & 15.2 & 0.0 & 75.7 \\
\hline 32 Itaguara & 4.5 & 0.8 & 138 & 0.5 & 120.4 & 0.2 & 263 \\
\hline 33 Itatiaiucu & $12.1 \rrbracket$ & 2.3 & 266 & 0.9 & 97.5 & 0.1 & 375.6 \\
\hline 34 Rio Manso & 18.2 & 3.4 & 19.9 & 0.1 & 21.7 & 0.0 & 59.9 \\
\hline Total & 536.5 & 100 & 30663.1 & 100 & 67168.4 & 100 & 98367.3 \\
\hline
\end{tabular}

Fonte: base de dados do modelo, MIP 2011.

A tabela 3, por seu turno, revela os coeficientes técnicos de uso da água (gasto com água em relação ao valor bruto de produção de cada setor do modelo). O coeficiente da indústria, por exemplo, indica que o uso da água representa em 
média $0,80 \%$ do valor bruto da produção do setor nos municípios da RMBH, ao passo que para a agropecuária o coeficiente gira em torno de $0,20 \%$.

Setorialmente, assume-se que estes coeficientes são idênticos para todos os municípios.

\section{Tabela 3 - Coeficientes técnicos no uso de água por setor}

\begin{tabular}{lr}
\multicolumn{1}{c}{ Setores } & $\begin{array}{c}\text { Coeficiente } \\
\text { técnico de água }\end{array}$ \\
\hline Agropecuária & $0,20 \%$ \\
Indústria & $0,80 \%$ \\
Eletricidade e & $0,18 \%$ \\
Gás & \\
Água e Esgoto & $0,21 \%$ \\
Transporte & $0,88 \%$ \\
Comércio & $0,53 \%$ \\
Serviços & $0,44 \%$ \\
\hline
\end{tabular}

Fonte: base de dados do modelo. Razão do gasto com Água e o Valor Bruto da Produção setorial.

\section{Simulações e resultados}

As simulações consistiram no corte de $1 \%$ na oferta de água no conjunto dos municípios da RMBH. Essa redução é obtida a partir da elevação do custo (em termos percentuais) da água em todas os municípios e para todos os usos. Assim, garante-se o princípio da eficiência econômica da restrição, pois todos os agentes sofrem a mesma elevação marginal de preços. Esta forma de simulação se aproximaria da imposição de uma sobretaxa (em termos percentuais) no custo da água para toda a região.

Adotamos como hipótese que o consumo total das famílias em cada região permanece fixo, assim as famílias realocam seu consumo em virtude da restrição da elevação direta do preço da água e dos demais preços. O efeito é uma redução no consumo de água e de bens ou serviços cujos preços relativos sofreram elevações. Para os setores produtivos, como não há substituto para o insumo água, o efeito é uma elevação nos seus custos de produção, e, portanto, redução da oferta e da demanda. Notadamente, como a água é um insumo relativamente mais importante na agropecuária e na indústria, esses setores apresentam as maiores quedas de atividade econômica e aumento de preços. O setor de serviços, com utilização muito baixa de água, pode ser beneficiado, pois a redução de atividade na agropecuária e na indústria acaba liberando fatores produtivos (capital e trabalho) que se tornam relativamente mais baratos. $\mathrm{O}$ 
investimento e o estoque de capital se ajustam entre os setores, supondo-se assim uma dinâmica temporal de médio-longo prazo (tipicamente, de 2 a 5 anos) para os ajustes da economia. Cabe ressaltar que modelagem estática é uma abordagem linear e, por conseguinte, quaisquer outras possibilidades para a extensão de cortes de oferta podem ser facilmente estimadas. O impacto de um choque exógeno de oferta em $30 \%$ sobre os níveis de preços das indústrias, por exemplo, é o triplo do impacto de um choque de $10 \%$.

De acordo com os resultados da simulação, o efeito sobre o preço da água é de uma elevação média de 7,3\% na RMBH, para uma redução de $1 \%$ no consumo total de água (todos os usos). Já o consumo familiar de água se reduz em torno de 2,6\%. Assim, a elasticidade implícita entre consumo familiar de água e preço é de 0,36. Já o efeito total sobre o uso de água mostra-se bastante inelástico na região, uma vez que a redução de consumo é $1 / 7$ da elevação dos preços. Assim, se a meta fosse uma queda de $20 \%$ no consumo total de água da RMBH, seria necessária uma elevação de preços de 146\%. Estes números indicam que o valor relativo da água nos custos de produção e na cesta de consumo das famílias é bastante baixo, daí a necessidade de elevações expressivas de preços para a obtenção de quedas significativas de consumo.

Pode-se intuir o efeito negativo será maior quanto maior a participação dos setores intensivos em água nas regiões. No caso da RMBH, municípios pequenos são mais dependentes da agropecuária (Floresta, Rio Manso e Mario Campos) e da Indústria (Mateus Lima, São J oaquim de Bicas, Taquaraçu de Minas). Belo Horizonte, por seu turno, tem maior participação de serviços na sua estrutura produtiva, e dessa forma menos afetada diretamente pelo corte de água como insumo. O mapa da Figura 6 revela este padrão regional de perdas, e o resultado de Belo Horizonte mostra-se bastante inferior à média da RMBH. 
Figura 6. Impactos simulados da restrição de água na RMBH variações no PIB e nos preços dos municípios

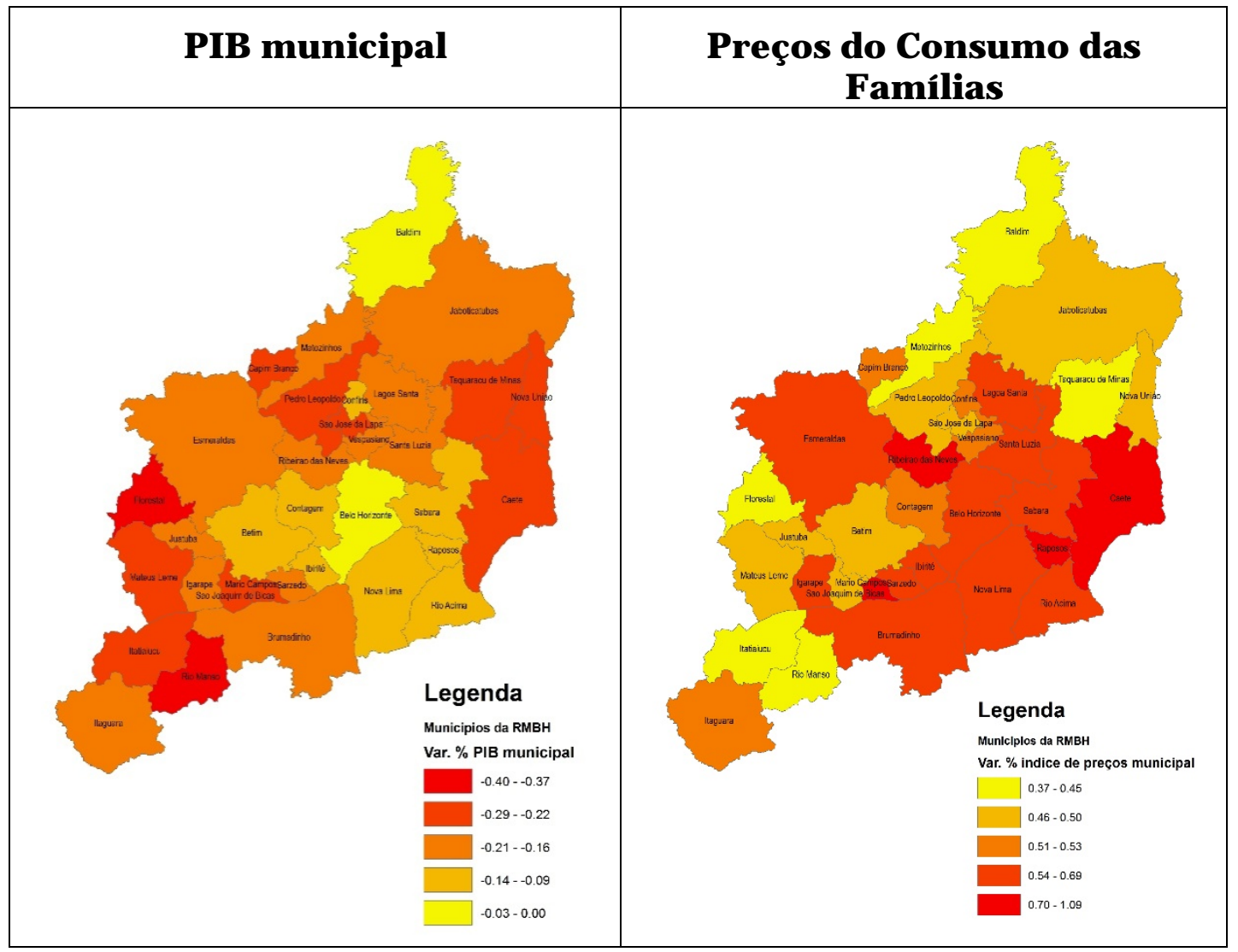

Fonte: elaboração própria a partir dos resultados das simulações

A Figura 7 revela o padrão de queda no consumo de água decorrente das restrições de oferta e elevação de preços. As taxas de variação no consumo residencial são bastante próximas da média, um resultado decorrente das elasticidades de gasto do consumo de água e da hipótese de consumo total constante. Já o consumo total de água cai de forma heterogênea na RMBH, fato determinado pela estrutura produtiva dos municípios: aqueles mais dependentes da indústria tendem a ter maior retração. 
Figura 7. Impactos simulados da restrição de água na RMBH variações no consumo de água total e residencial

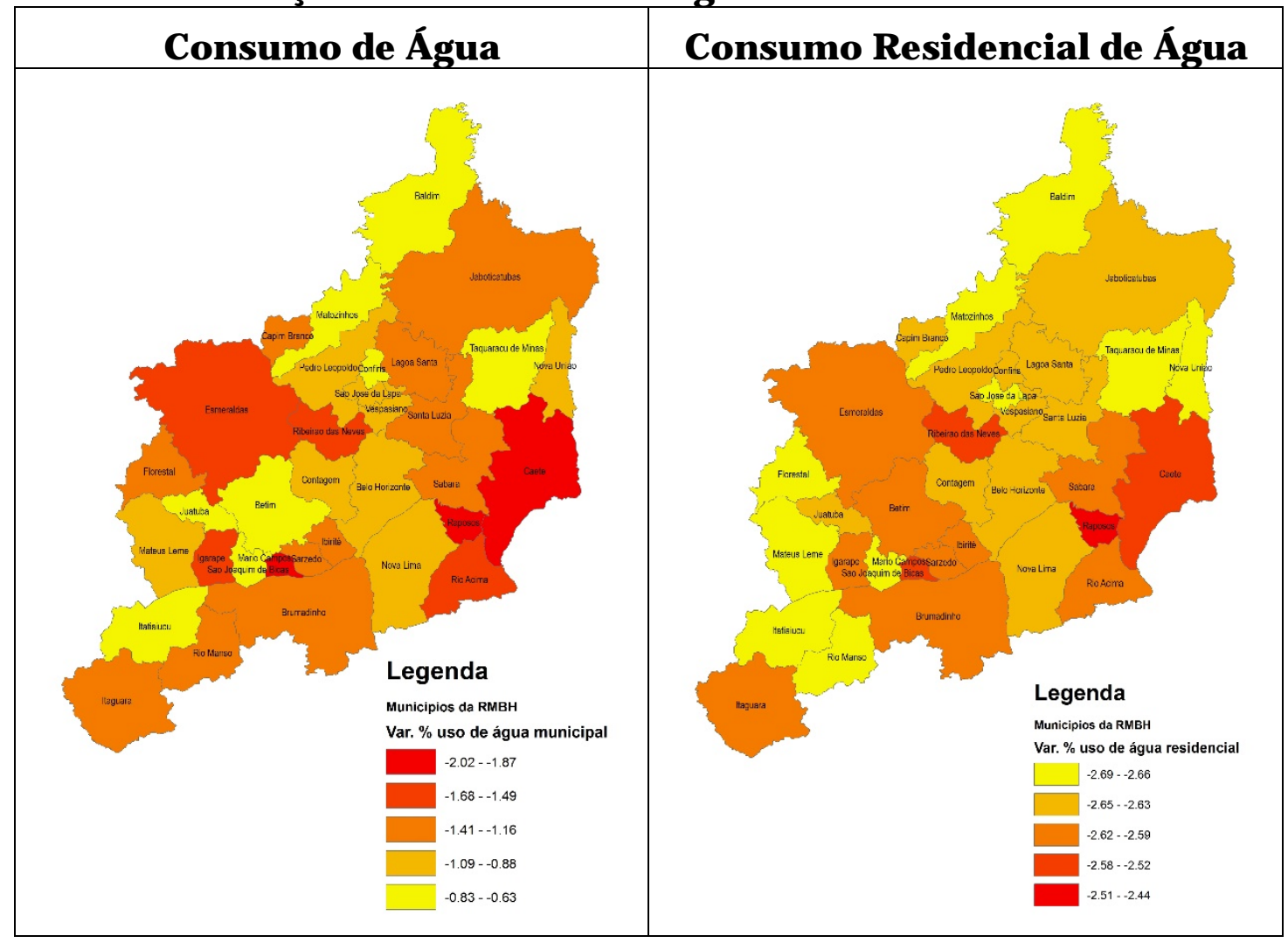

Fonte: elaboração própria a partir dos resultados das simulações

A Figura 8 mostra o impacto sobre o PIB setorial. As maiores taxas de queda de atividade são na agropecuária, seguido da indústria. O setor de Comércio apresenta taxas menores, e o de serviços mostra inclusive regiões com impactos positivos, como no município de Belo Horizonte. Os resultados desse município mostram que a contribuição positiva do resultado de serviços no município permite contrabalançar o efeito negativo dos demais setores, resultando no efeito próximo de zero para a capital do estado.

Os resultados indicam que municípios com pior distribuição de renda (consumo residencial de água mais elevado) e mais dependentes da indústria seriam mais afetados, o contrário ocorreria com municípios especializados nos setores de serviços. Os números mostram que a restrição de água resultaria na ampliação da desigualdade regional entre os municípios da RMBH. 
Figura 8. Impactos simulados da restrição de água na RMBH variação \% do PIB setorial por município

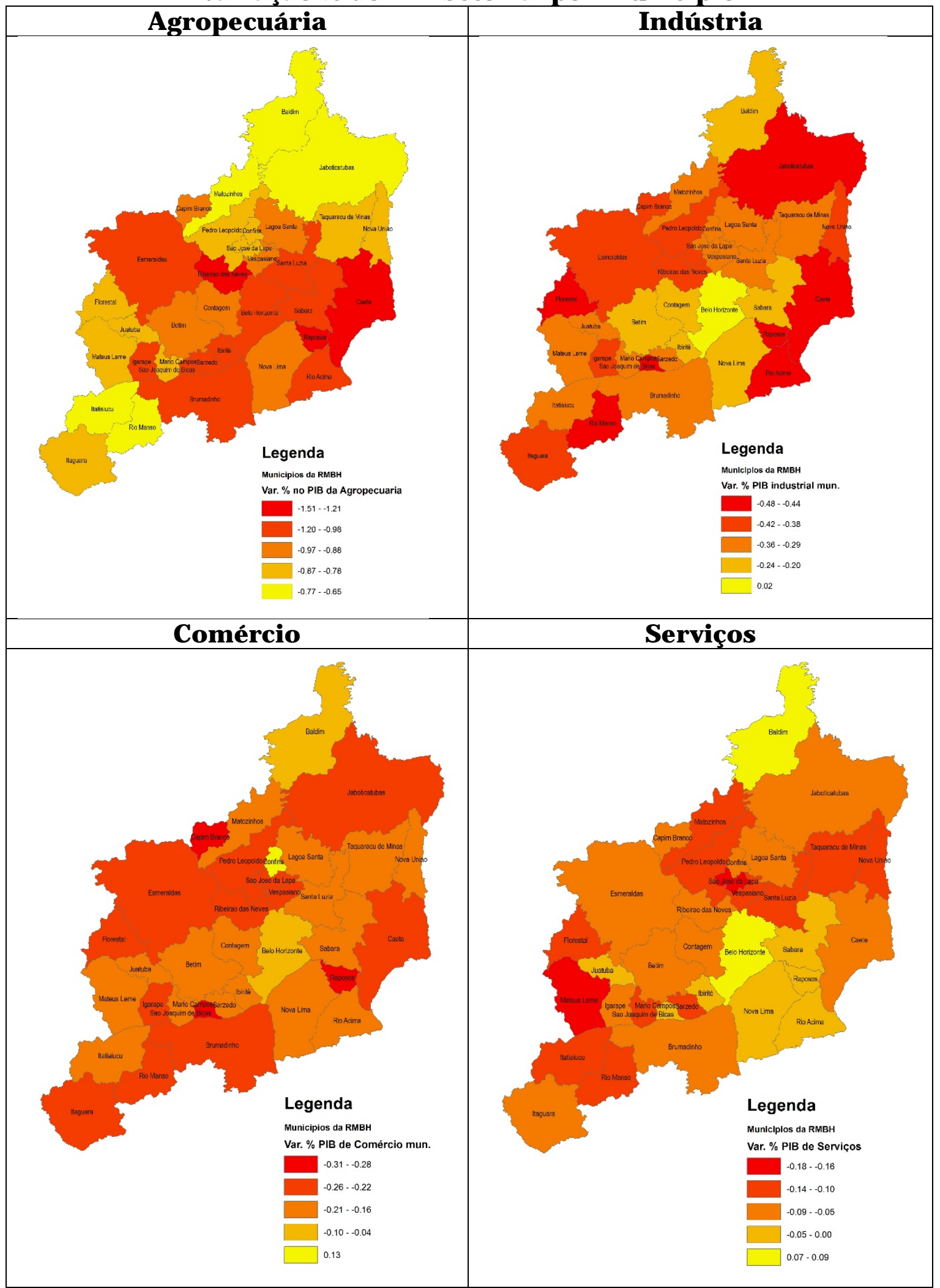

Fonte: elaboração própria a partir dos resultados das simulações 


\section{Considerações Finais}

Este trabalho analisou a questão do uso de água na RMBH procurando projetar o impacto de restrições de oferta e de elevação de tarifas. Esses elementos tornaram-se relevantes a partir do início de 2015 quando foram noticiados os baixos níveis dos reservatórios da região e o poder público passou a atuar com campanhas de incentivo à economia de água. Entretanto, no médio e longo prazo, se a situação de escassez persistir ou se tornar mais grave, é provável que a RMBH seja foco de políticas de restrição ao uso de água, seja por meio de rodízios de fornecimento ou multas por consumo excessivo. Assim, torna-se relevante estimar o impacto que estas políticas podem ter na região, levando-se em conta ainda a conjuntura de baixo crescimento econômico e elevação de desemprego observada a partir de 2015.

Em termos metodológicos, este trabalho parte da literatura e dos conhecimentos aplicados em equilíbrio geral e apresenta o primeiro modelo em escala municipal para o Brasil, especificado para os 34 municípios da RMBH. Além disso, o modelo detalha a utilização da água nos setores produtivos e no consumo familiar, possibilitando a análise de restrições de oferta ou elevações de preço desse serviço.

Os dados que alimentam o modelo mostram que o custo com a água para os setores produtivos e famílias é relativamente pequeno. Entre os setores, o custo com água é menor que $1 \%$ dos custos totais de produção; entre as famílias está em torno de $0,5 \%$ a $4 \%$ do gasto total de bens e serviços consumidos. Tomandose estes números como padrão para a economia brasileira e suas regiões, notase que políticas de elevação de preços (multas) tendem a ter um impacto relativamente pequeno na redução de seu uso. Não por acaso, as políticas mais utilizadas em momentos de crise de abastecimento são de rodízio, que representam um corte direto na oferta (disponibilidade) do serviço.

Os resultados das simulações indicam que para um corte de $1 \%$ no consumo total de água na RMBH seria necessária uma elevação média de tarifas de 7,3\%. Logo, o efeito total sobre o uso de água mostra-se bastante inelástico, uma vez que a redução de consumo é $1 / 7$ da elevação dos preços. Se a meta fosse uma queda de $20 \%$ no consumo total de água da RMBH, seria necessária uma elevação de preços de $146 \%$. Já para o consumo familiar de água a elasticidadepreço implícita nos resultados é de 0,36 , ou seja, uma elevação de $1 \%$ nos preços diminuiria o consumo em $0,36 \%$.

Outro resultado importante é o impacto municipal da restrição de água. Dada a estrutura produtiva dos seus municípios, a capital, Belo Horizonte, seria a menos afetada, e municípios mais pobres seriam os mais afetados. Este resultado ressalta que municípios com pior distribuição de renda (consumo residencial de água mais elevado) e mais dependentes da atividade agrícola e pecuária seriam mais afetados. Dessa forma, a restrição de água resultaria na ampliação da desigualdade regional entre os municípios da RMBH. 


\section{Referências}

Agência Nacional De Águas, Ana. Atlas Brasil - Abastecimento Urbano De Água: Resultado Por Estado, Volume 2. Brasília, 2010, 92p.

Agência Nacional De Águas, Ana. Conjuntura Dos Recursos Hídricos No Brasil: Informe 2014. 2014, $30 \mathrm{P}$.

Agência Nacional De Águas, Ana. Abastecimento Urbano De Água: Região Metropolitana De Belo Horizonte. 2015

Berritella, M.; Hoekstra, A. Y.; Rehdanz, K.; Roson, R.; Tol, R. S. J . The Economic Impact Of Restricted Water Supply: A Computable General Equilibrium Analysis, Water Research, Vol. 41, P. 1799-1813, 2007.

Browuer, R.; Hofkes, M. Integrated Hydro-Economic Modelling: Approaches, Key Issues And Future Research Directions, Ecological Economics, Vol. 66, P. 16-22, 2008.

Dixon, P. B.; Parmenter B. R.; Sutton, J. M.; Vincent D. P. Orani: A Multisectoral Model Of The Australian Economy. Amsterdam: North-Holland, 1982. $372 \mathrm{P}$.

Fadali, E.; Rollins, K.; Stoddard, S. Determining Water Values With Computable General Equilibrium Models. Washington, Dc: National Academy Of Public Administration, 2012.

Ferreira Filho, J . B.; Horridge, J . M. Climate Change Impacts On Agriculture And Internal Migrations In Brazil. In: 14 ${ }^{\text {th }}$ Annual Conference On Global Economic Analysis 2011, Venice Proceedings Of The 14 ${ }^{\text {th }}$ Annual Conference On Global Economic Analysis, 2011.

Ferreira Filho, J . B.; Horridge, J . M. Ethanol Expansion And Indirect Land Use Change In Brazil. Land Use Policy, Vol. 36, P. 595-604, 2014.

Horrigde, M. Preparing A Term Bottom-Up Regional Database. Preliminary Draft, Centre Of Policy Studies, Monash University, 2006.

Horridge, J . M.; Madden, J .; Wittwer, G. The Impact Of The 2002-2003 Drought On Australia. J ournal Of Policy Modeling, V. 27, N. 3, 2005/4, P. 285308, 2005.

Ministério Do Planejamento, Orçamento E Gestão. Impactos Econômicos Da Carteira De Investimentos. In: Estudo Da Dimensão Territorial Para O Planejamento, Volume Vi. Mpog, Secretaria De Planejamento E Investimentos Estratégicos, Brasília, 2008.

Miller, R.; Blair, P. Input-Output Analysis: Foundations And Extensions. New J ersey: Prentice-Hall, 2009. 782p.

Peter, M. W.; Horridge, M.; Meagher, G. A.; Parmenter, B. R. The Theoretical Structure Of Monash-Mrf. Australia: Monash University, Centre Of Policy Studies, Impact Project: 121 P., 1996.

Reilly, J .; Paltsev, S.; Felzer, B.; Wang, X.; Kicklighter, D.; Mellilo, J .; Prinn, R.; Sarofim, M.; Sokolov, A; Wang, C. Global Economics Effects Of Changes In 
Crops, Pasture, And Forests Due Changing Climate, Carbon Dioxide, And Ozone. Energy Policy, Vol. 35, P. 5370-5383, 2007.

Van Heerden, J .; Blignaut, J .; Horridge, M. Integrated Water And Economic Modelling Of The Impacts Of Water Market Instruments On The South Africa Economy, Ecological Economics, Vol. 66, P.105-116, 2008.

Wittwer, G. Economic Modeling Of Water. London: Springer, 2012, 186 P. 